\title{
Kılavuzlu Barajı Sulama Kanalında Su Derinliğinin Hec-Ras Programı İle Modellenmesi
}

\author{
Mehmet ÜNSAL ${ }^{1}$, Alişan NALCIOĞLU ${ }^{2}$ \\ ${ }^{1}$ Kahramanmaraş Sütçü İmam Üniversitesi, İnşaat Mühendisliği, Kahramanmaraş, Türkiye \\ ${ }^{2}$ Kahramanmaraş Sütçü İmam Üniversitesi, İnşaat Mühendisliği, Kahramanmaraş, Türkiye
}

\begin{abstract}
ÖZET: Su, bilinen tüm yaşam biçimleri için gerekli ve vazgeçilmez olan kokusuz bir maddedir. Su, canlıların yaşaması için hayati bir öneme sahiptir. Su içme suyu, evsel kullanım, tarımsal sulama, bilim, sanayinin yanı sıra hidroelektrik santrallerde ilaç yapımından tekstil ve kozmetiğe kadar birçok alanda ihtiyaçlara cevap verir. Bu ihtiyaçlardan en büyük paya sahip olan tarımsal arazilerin sulanmasıdır. Kaynaktan ihtiyaç bölgesine suyun iletimini sağlayan yapılar kanallardır. Kanallar genel olarak Açık ve Kapalı (boru tipi) olarak ikiye ayrılır. Açık kanallar dikdörtgen, trapez, üçgen ve yarım daire gibi farklı kesitlerde bulunabilir. Bu çalışmada, Kılavuzlu kanalı su derinliğinin HEC-RAS programı ile modellenmesi amaçlanmıştır. Çalışma sonucunda proje değerleri ile model sonuçlarının uyumlu olduğu görülmüştür.
\end{abstract}

Anahtar Kelimeler: HEC-RAS, Kllavuzlu Sulama Kanalı

\section{Modelling of Water Depht in Irrigation Channel of Kılavuzlu Dam By Hecras Programme}

\begin{abstract}
Water is the necessary for the all kind of life. Water is indispensable, odorless substance.Water is very important for the all of the life. Water used for drinking water, domestic water, irrigation, science and industry as well as to hydroelectric power plan, medicine and cosmetic. All of these section, irrigation has important. Water is transfert from water resource to demand area with water channels. Generally channels has two type, these are open and close (pipe type). Open channels can be rectangle, trapezoidal, triangular and semi-circle. In this study, water depht is modelled by HEC-RAS software in irrigation channel Kilavuzlu Dam.As a result there is a good agreement between model and project values.
\end{abstract}

Keywords: HEC-RAS, Irrigation Channel of Kllavuzlu Dam

\section{GİRIŞ}

İnsanoğlu, bitkiler ve hayvanlar dünyada suya bağlı bir yaşam sürmektedir. Su olmazsa yaşam olmaz ve buna bağlı olarak tarım yani besin ihtiyaçları karşılanması mümkün değildir.Tarihe baktığımızda insanlar yerleşim yerlerini suya yakın yerlere kurmak istemişlerdir, yine savaşlarda suya yakın yerleri cephe edinen ülkeler avantajlı ülkeler olmuştur. Su insanlar tarafından çeşitli ihtiyaçları karşılamak için kullanılabilir tarih boyunca su insan vücudu için yaşam kaynağı olmasının yanında tarımsal üretimler ve hayvancılıkta kullanılmış olup günümüzde artık HES'ler kurularak enerji üretimi içinde kullanılmaya başlanmıştır.Ülkemiz tarihinde M.Ö. 8.yüzyılda yapılmış olan Van yöresindeki Şamram sulama kanalı ve bazı barajlar, M.S. 16.yüzyılda Mimar Sinan tarafindan yapıllmış olan Taşlı müsellim-Edirne, Kırkçeşme-İstanbul su iletim sistemleri ve kemerleri, M.S. 17. ila 19.yüzyıllarda inşa edilmiş olan İstanbul su temini bentleri başta olmak üzere, bazıları günümüzde de kısmen veya tümüyle kullanılmaya devam etmektedir.(8) Mevcut su kaynaklarından suyu ihtiyaç bölgesine ileten yapılar kanallardır. Kanallar iki farklı türdedir, ilki gelenekse açık kanallar olup su iletiminde büyük paya sahip olan kanallardır. İkinci kanal tipide kapalı (boru tipi) kanallardır.(4) İki kanal tipinin de olumlu ve olumsuz yanları vardır. Açık kanallar uzun mesafelerde kapalı kanallara göre maliyet olarak daha uygundur fakat atmosfer ile temas ettiğinden dolayı buharlaşma meydana gelerek suda kayıplar yaşanır. Kapalı kanallar ise su iletimi sırasında açık kanallar kadar kayıp yaşatmazken ciddi bir maliyet oluşturur. Açık kanallarda kullanılan malzeme seçeneğinin fazla olmasından dolayı pürüzlülük sınırları çok geniştir. Açık kanallarda serbest su yüzeyinin durumu zaman ve mekâna bağlı olarak değişiklik gösterir. Kanallar arazinin yapısına göre dikdörtgen, trapez, üçgen ve dairesel gibi farklı kesitlerde bulunabilir.(9) Kapalı kanal tipleri galeriler ve boru tipi olarak kendi içinde iki farklı şekilde iletim sağlarlar. Galerilerde debinin şiddetine göre kesitler belirlenir küçük debilerde dairesel kesit, büyük debilerde ise at nalı, dikdörtgen gibi kesitler tercih edilir. Boru tipi kapalı kanallar ise font, çelik, plastik ve betonarme boru olmak

\footnotetext{
*Sorumlu Yazar: Mehmet ÜNSAL munsal@ksu.edu.tr
} 
üzere 4 'e ayrılır. Bunlardan en eski ve en çok kullanılanı font tipi borulardir.(7)

\section{HEC-RAS TANIMI VE DİĞER PROGRAMLARLA İLIŞKİSI}

HEC-RAS programı, Amerika Birleşik Devletleri Askeri Mühendislik Biriminin bir bölümü olan Hidroloji Mühendislik Merkezi Hidrologic Engineering Center (HEC) tarafindan geliştirilmiş bir yazılımdır. Program tek boyutlu kararlı ve kararsız akımların analizini, sediment taşınımı analizi ve su sıcaklığı analizi yapılabilmektedir. Su yüzeyi profillerinin elde edilmesi için 1995 yılından bu yana HEC-RAS programı kullanılmaktadır.(1)HEC-GeoRAS, HEC-RAS programı için tasarlanmış bir arayüzdür.(6) HEC-RAS ise tek boyutlu hidrodinamik hesapları yapabilecek şekilde tasarlanıp geliştirilmiştir. Program; kararlı akım, kararsız akım, nehir rejimi, sel rejimi ya da karışık rejim durumlarında hesap yapabilmektedir. Hec-GeoRAS; ArcGIS ve Hec-RAS arasında köprü görevi yapıp, HecRAS'ta hidrolik analiz yapmak için gerekli nehir geometrisi ile ilgili verilerin ArcGIS ile elde edilip HecRAS'a aktarılmasını sağlamaktadır. Akarsu kolları ve en kesitler Hec-GeoRAS'da tanımlanması oldukça kolaydır, diğer katmanlar Hec-RAS ortamında da girilebilir.(3) HEC-RAS tek boyutlu, sürekli akımlara ait su yüzeylerinin hesaplandığı ve süreksiz akımlara ait modellemelerin yapıldığı, veri saklama ve yönetim kapasitesi olan bir hidrolik yazılımdır.(3) Hidrolik analizden önce hidrolojik analiz yapılması esastır.HECRAS programında inşaat mühendislerini genel olarak ilgilendiren taşkın analizi ve kanal tasarlanmasıdır. Kanal tasarlarken çalışma yapılan suyolu, belirlenen geometrik şeklin yanında kullanılan malzemeye uygun manning katsayısı, suya ait debi, akış eğimi, akım türü gibi bilgilerin veri girişi yapılır.Herhangi bir çalışmada taşkın hidrografları bulunduktan sonraki adım hidrolik model çalışmalarıdır. Suyollarında ve çevrelerindeki sel yataklarında, su basma alanlarının ve su derinliklerinin bulunması gibi hidrolik analizler için geliştirilen çeşitli hidrolik model tipleri bulunmaktadır. Bunlardan bir kısmı CBS ile entegre edilerek çalışabilecek hale getirilmiş veya yazılan ara yüzlerle bu ișlem sağlanmıştır. Bu tip modellerden en çok kullanılan bir tanesi Danimarka Hidrolik Enstitüsü'nün hazırladığı MIKE 11 model serisinin hidrodinamik (HD) modülü, diğeri de Amerikan Hidrolojik Mühendislik Merkezi’nin (HEC) HEC-RAS modelidir.(5)

\section{HEC-RAS KULLANILARAK YAPILAN LITERATÜR ÇALIŞMALARI}

HEC-RAS programı kullanılarak daha önce yapılan bazı çalışmalar;Uçar (2010) , yılında yaptı̆̆ı çalışmada Trabzon Değirmendere havzasında taşkın riskini CBS ve HEC-RAS programı kullanılarak tespit etmiştir. Riskli bölgenin çok olduğunu gözlemleyerek yapısal ve yapısal olmayan çözümler sunmuştur.Tuncer (2011), yılında yaptı̆̆ı çalışmada İstanbul Nakkaş deresinde mevcut bilgileri kullanarak kanal tasarlanmış ve kanalda meydana gelen su yüksekliğini tespit etmiştir.Eryılmaz Türkkan ve Korkmaz (2015), yılında yaptığı çalışmada Bursa'da bulunan Kaplıkaya deresinde ARC-GIS ve HEC-RAS programlarını kullanarak taşkın durumunu araştırmıştır. Riskli bölgenin çok olduğunu gözlemleyerek yapısal ve yapısal olmayan çözümler sunmuştur.Bayazıt ve Bakış (2015), yılında yaptığı çalışmada Sakarya havzasının alt havzası olan Seydisuyu çayının 50, 100 ve 1000 yıllık debi değerleri ve proje bilgileri programa girerek taşkın su seviyesi ve tarım arazilerine olan etkisini tespit etmiştir.

\section{MATERYAL}

Kilavuzlu baraj1, toprak gövde dolgu tipi olan, gövde hacmi $3.497 .000 \mathrm{~m}^{3}$, akarsu yatağından yüksekliğ $59,00 \mathrm{~m}$, normal su kotunda göl hacmi $69,00 \mathrm{hm}^{3}$, normal su kotunda gölalanı $3,10 \mathrm{~km}^{2}$ olan bir barajdır.(6) Barajların yapım amaçları o bölgede bulunan ihtiyaç doğrultusunda belirlenir. Kılavuzlu barajı hem sulama hem de enerji üretmek amaciyla 1996 - 2001 yılları arasında inşa edilen barajdır. Barajın devamı niteliğinde olan su iletim kanalının tamamlanmasiyla Kahramanmaraş, Gaziantep ve Hatay illeri sınırlarında bulunan 178 bin hektarlık tarım arazilerinin sulanmasını amaçlamıştır. Kılavuzlu sulama projesi iki etaptan oluşmaktadır. Projenin birinci etap çalışmaları tamamlanmış olup Hatay'a uzanan ikinci etap çalışmaları devam etmektedir. Bu çalışmada, Akdeniz bölgesi Kahramanmaraş ili Onikişubat ilçesi Ceyhan nehri üzerinde Kılavuzlu barajının su iletim kanalının $2+287,68-2+481,80 \mathrm{~km}$ arasında gerçekleşmiştir.(Şekil 1)Çalışmada kullandığımız proje değerleri Tablo 1 'de gösterilmiş̧tir.

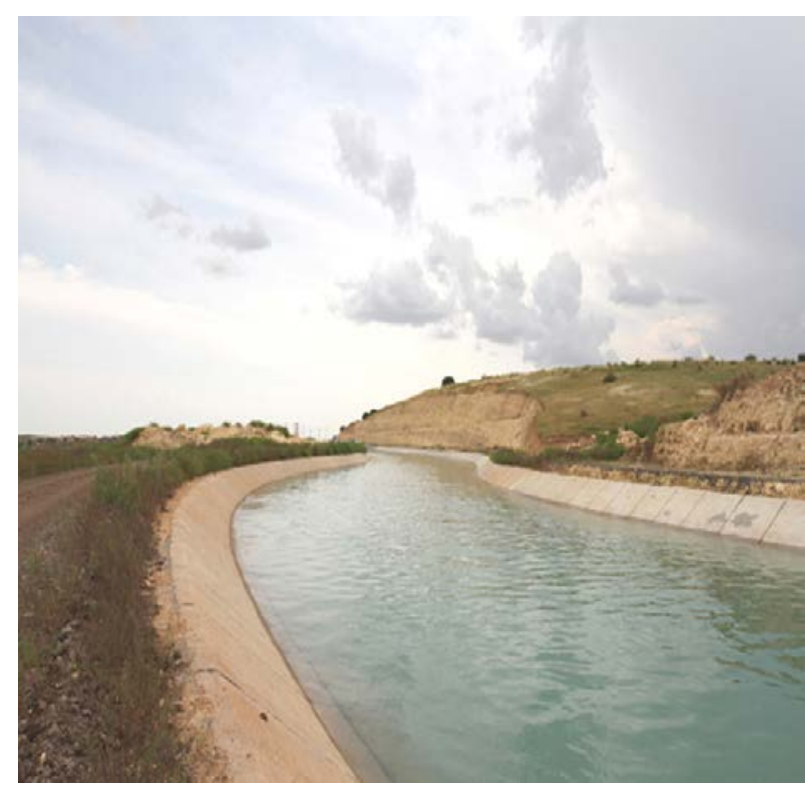

Şekil 1. Kılavuzlu Baraj1 Sulama Kanalı 
Tablo 1. Proje Değerleri

\begin{tabular}{|c|c|}
\hline Kanal Tipi & Trapez \\
\hline $\begin{array}{c}\text { Kanal Uzunluğu (Çalışma } \\
\text { yapıllan uzunluk) }\end{array}$ & $194.12 \mathrm{~m}$ \\
\hline Kullanılan Malzeme & Beton \\
\hline Manning Katsayıs1 & 0.015 \\
\hline Debi (m³sn) & 80 \\
\hline Suyun Eğimi & 0.0001 \\
\hline
\end{tabular}

\section{HEC-RAS UYGULAMA AŞAMALARI}

HEC-RAS programinda nehir profilinden yararlanılarak kanalın eğimi memba ve mansapta aynı değer alınmıştır.( $j=0.0001)$. Manning katsayısı beton kanal olduğu için 0.015 alınmıştır. Akımın rejimi karışık akım olarak tanımlanmıştır. Kanal kesiti ile ilgili bilgiler projeden alınarak kanalın kesiti oluşturulmuştur.

Çalışmamızda ilk olarak suyolu çizilmiş ve enterpolasyon (programda çözümleme yaparken polinom enterpolasyon yöntemi kullanılmaktadır) yapılarak kesitler oluşturulmuştur(Şekil2).Kesitler oluşturulduktan sonra kesitlere ait bilgiler girilmiştir (Şekil 3). Mevcut su bilgileri girilip program çalıştıktan sonra kesitlerde bulunan su yükseklikleri tespit edilmiştir (Şekil 4). Analiz sonucu bulunan veriler genel tabloda gösterilmiştir(Şekil 5).

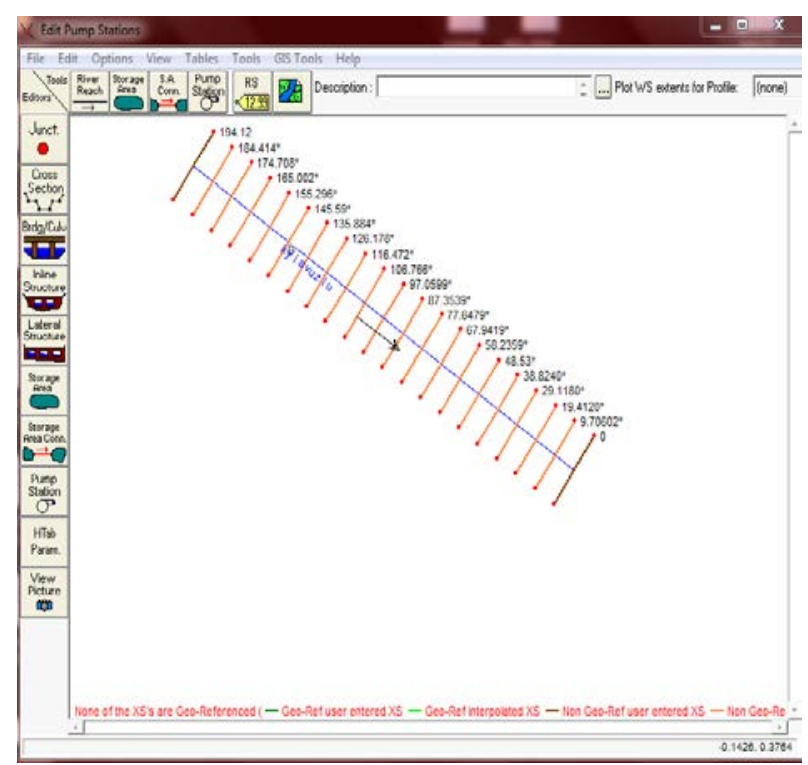

Şekil 2. Su Yolu Çizimi Kesit Oluşturma

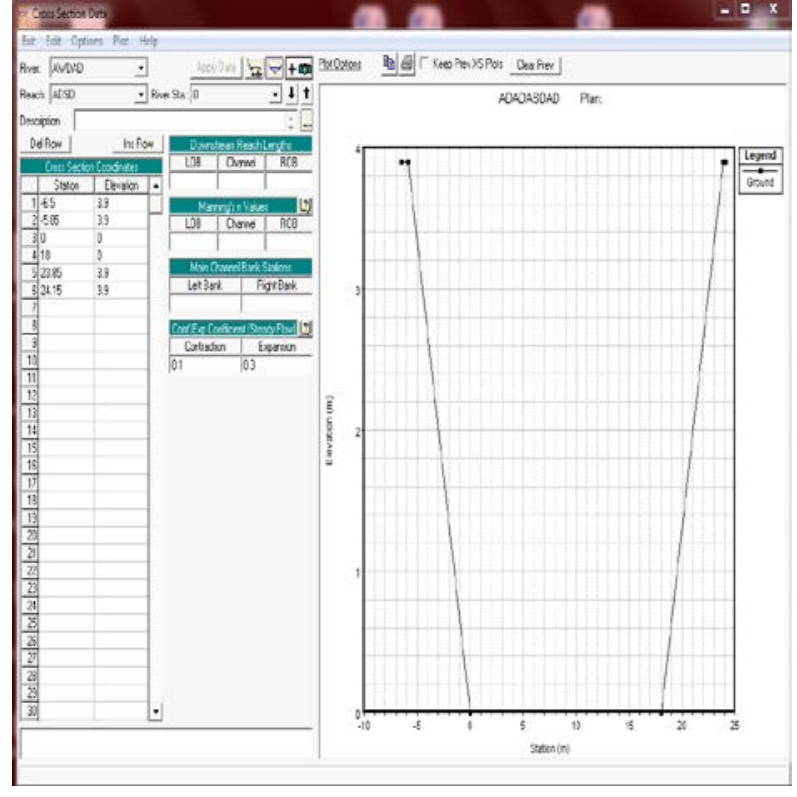

Şekil 3. Kesit Bilgilerinin Girilmesi

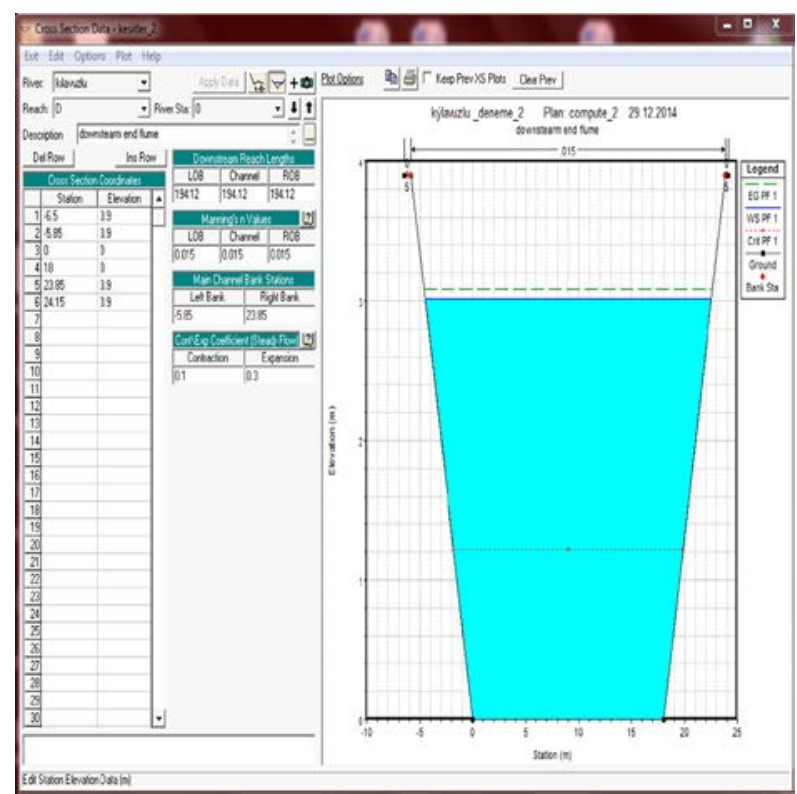

Şekil 4. Su Yüksekliği 


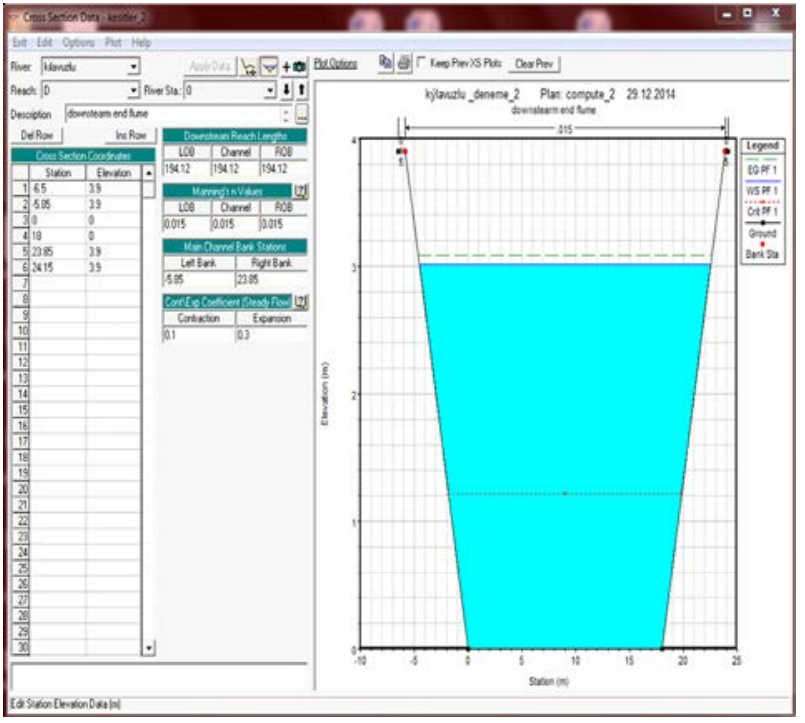

Şekil 5. Genel Sonuç Tablosu

$\mathrm{Bu}$ çalışma Kılavuzlu kanalının 2+287,68$2+481.80 \mathrm{~km}$ arasında gerçekleştirilmiştir. Kanal boyunca toplam 21 kesit alınmıştır. Her kesitte elde edilen değerlerin proje değerleri ile $\% 100$ e yakın uyumlu olduğu aşağıda verilen Tablo 2 ve Şekil 6 da gösterilmiştir. Buradan kanal hesaplarında Hec-Ras programının oldukça etkili ve başarılı sonuçlar verdiği görülmüştür.

Tablo 2. Kesit Değerleri

\begin{tabular}{|c|c|c|}
\hline $\begin{array}{c}\text { Kesit } \\
\text { No }\end{array}$ & $\begin{array}{c}\text { HEC-RAS } \\
\text { DEĞERLERI }\end{array}$ & $\begin{array}{c}\text { PROJE } \\
\text { DEĞRLERI }\end{array}$ \\
\hline 1 & 3.03 & 3.02 \\
\hline 2 & 3.03 & 3.02 \\
\hline 3 & 3.03 & 3.02 \\
\hline 4 & 3.03 & 3.02 \\
\hline 5 & 3.02 & 3.02 \\
\hline 6 & 3.02 & 3.02 \\
\hline 7 & 3.02 & 3.02 \\
\hline 8 & 3.02 & 3.02 \\
\hline 9 & 3.02 & 3.02 \\
\hline 10 & 3.02 & 3.02 \\
\hline 11 & 3.02 & 3.02 \\
\hline 12 & 3.02 & 3.02 \\
\hline 13 & 3.02 & 3.02 \\
\hline 14 & 3.02 & 3.02 \\
\hline 15 & 3.01 & 3.02 \\
\hline 16 & 3.01 & 3.02 \\
\hline 17 & 3.01 & 3.02 \\
\hline 18 & 3.01 & 3.02 \\
\hline 19 & 3.01 & 3.02 \\
\hline 20 & 3.01 & 3.02 \\
\hline 21 & 3.01 & 3.02 \\
\hline & & \\
\hline
\end{tabular}

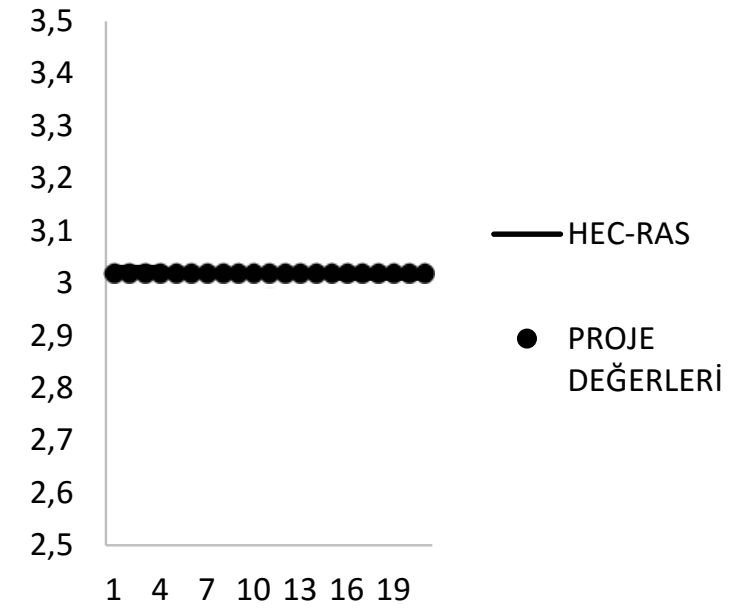

Şekil 6. Karşılaştırma Grafiğgi

\section{SONUÇLAR}

$\mathrm{Su}$, canlıların yaşaması için hayati bir öneme sahiptir. Dünya üzerinde farklı şekillerde bol miktarda bulunur. Su içme suyu, evsel kullanım, tarımsal sulama, bilim, sanayinin yanı sıra hidroelektrik santrallerde ilaç yapımından tekstil ve kozmetiğe kadar birçok alanda ihtiyaçlara cevap verir. Bu ihtiyaçlardan en büyük paya sahip olan tarımsal arazilerin sulanmasıdır. Kaynaktan ihtiyaç bölgesine suyun iletimini sağlayan yapılar kanallardır. Bu çalışma, Kılavuzlu Barajı su iletim kanalının 2+287,68- 2+481,80 $\mathrm{km}$ arasında gerçekleştirilmiştir. Çalışmanın sonucunda model değerleri ile proje değerlerinin uyumlu olduğu görülmüştür. Kanal tasarlanmasında HEC-RAS programını kullanarak her noktada sonuçlara daha hızlı ulaşabileceği görülmektedir.

\section{KAYNAKLAR}

[1].TUNCER, İ. 2011. Açık Kanallarda Su Yüzü Profilinin Belirlenmesi Nakkaş Dere Örneğinde bir Hec-Ras Uygulamasi, Gazi Üniversitesi Fen Bilimleri Enstitüsü İnşaat Mühendisliği. Yüksek Lisans Tezi. Ankara.

[2]. DEĞİRMENCİ, İ. 2010. Su ve Toprak Kaynaklarının Planlanmast

[3].http://www.hec.usace.army.mil/software/hec-ras (Erișim Tarihi: 14.03.2015).

[4]. UÇAR, İ. 2010. Trabzon Değirmendere Havzası'nda Coğrafi Bilgi Sistemleri Ve Bir Hidrolik Model Yardımıyla Taşkın Analizi Yapılması, Gazi Üniversitesi Fen Bilimleri Enstitüsü İnşaat Mühendisliği. Yüksek Lisans Tezi. ANKARA

[5]. USUL, N. 2008 Coğrafi Bilgi Sistemleri Teknikleri Kullanılarak Taşkın Risk Haritalarının Çıkarılması, Taşkın Konferansı, EDİRNE

[6]. ERYILMAZ TÜRKKAN, G. 2015 Kapllkaya Deresinin Sayısal Model Ile Taşkın Analizi Yapılmasi, BURSA 
[7]. KARPUZCU, M. 2005 Su Temini ve Çevre Sağllğl, ISTANBUL

[8]. BİLDIRICİ, M. 2009 Tarihi Su Yapılarl, KONYA

[9]. BULU, A. Ve YILMAZ, E. 2002 Serbest Yüzeyli Akımlarda Pürüzlülük Katsayısı Belirlenmesi, İSTANBUL

[10]. www.dsi.gov.tr (Erişim Tarihi: 23.02.2016) 